Published in final edited form as:

Heart Fail Rev. 2010 May ; 15(3): 229-238. doi:10.1007/s10741-008-9095-9.

\title{
Genomics, heart failure and sudden cardiac death
}

\author{
Dawood Darbar \\ Divisions of Cardiovascular Medicine and Clinical, Pharmacology, Vanderbilt University School of \\ Medicine, 2215B Garland Avenue, Room 1285A, MRB IV, Nashville, TN 37232, USA, e-mail: \\ dawood.darbar@vanderbilt.edu
}

\section{Abstract}

Sudden cardiac death (SCD) is among the most common causes of death in developed countries throughout the world. Despite decreased overall cardiac mortality, SCD vrates appear to be increasing in concert with escalating global prevalence of coronary disease and heart failure, the two major conditions predisposing to SCD. This unfavorable trend is a consequence of our inability to identify those who will die suddenly from lethal ventricular arrhythmias and to develop effective therapies for all populations at risk. The known risk factors for SCD lack the predictive power needed to generate preventive strategies for the large number of fatal arrhythmic events that occur among lowerrisk subsets of the population. Even among recognized high-risk subsets, prediction of SCD remains challenging. With the exception of the implantable cardioverter defibrillator (ICD) there are few effective strategies for the prevention and treatment of SCD. This article discusses the prospect of genomic science as an approach to the identification of patients at high-risk for SCD. While the final common pathway for SCD is malignant ventricular arrhythmias, there are many potential contributors, pathways, and mechanisms by which common genetic variants (polymorphisms) could affect initiation and propagation of life-threatening cardiac arrhythmias. Recent advances in genomic medicine now provide us with novel approaches to both identify candidate genes/pathways and relatively common polymorphisms which may predispose patients to increased risk for SCD. Improved understanding of the relationship between common polymorphisms and SCD will not only improve risk stratification such that ICDs can be targeted to those patients most likely to benefit from them but also provide new insight into the pathophysiology of SCD.

\section{Keywords}

Sudden cardiac death; Genomics; Heart failure; Single nucleotide polymorphisms

\section{Heart failure and SCD}

Heart failure (HF) afflicts approximately 5 million people in the United States, with 550,000 new cases reported annually, but as the population ages both the incidence and prevalence is expected to rise [1]. HF is associated with high mortality and is reportedly responsible for 300,000 deaths annually in the US [1]. Prior to advent of neuro-hormonal antagonists, the mean duration of survival after onset of HF was 1.7 years for men and 3.2 years for women, with only half of patients still alive after 5 years of onset [2]. The two modes of death in patients with $\mathrm{HF}$ are circulatory failure due to progressive left ventricular (LV) dysfunction associated with gradual worsening of symptoms, or sudden cardiac death (SCD) in relatively clinically stable patients [3].

Although the proportion of sudden deaths in published trials varies significantly, probably due to varying interpretations of reported modes of death, clinical trials data suggests that SCD accounts for approximately one-third of all HF deaths [4]. Epidemiologic evidence from the Framingham heart study suggests that about one-half of all deaths due to HF occur within $1 \mathrm{~h}$ 
of new symptoms in patients who appeared to be clinically stable [5]. In most cases, the mechanism is the rapid onset of a ventricular tachyarrhythmia, progressing to ventricular fibrillation (VF) and hemodynamic compromise.

The burgeoning public health problem of SCD is all too familiar to the clinical and research communities, yet progress in developing effective approaches to prevent SCD has been difficult to achieve. Despite over two decades of federal and industrial support for the evaluation of several hundred compounds, there are few antiarrhythmic drugs that reduce SCD incidence, even in high-risk pathologies. In contrast, the implantable cardioverter-defibrillator (ICD) is a proven therapy in preventing SCD in HF populations [6-9]. These devices, however, are expensive requiring medical resources not readily available to many segments of the population. Furthermore, an empiric approach of primary prophylactic ICD implantation for all HF patients with ejection fraction $\leq 35 \%$ and mild to moderate HF symptoms may prove difficult to sustain financially even in developed countries. Although optimization of ICD use continues to evolve, these devices may not deliver therapies in as many as half of the recipients. In addition, the fact that up to $50 \%$ of heart failure patients will experience death due to progressive $\mathrm{HF}$ and not malignant ventricular arrhythmias attests to the importance of judicious use of ICDs in this population. Over the last decade, the number of patients needed to treat to prevent one SCD has also risen from one in four patients to one in 14 [10]. The multi-center ICD trials, however, have failed to identify meaningful biological markers indicating elevated risk of SCD in specific individuals with differing cardiac pathologies.

\section{Risk stratification of SCD}

Despite declining cardiac mortality rates over the past decade, the proportion of cardiac deaths that are sudden has increased during a time when major advances in device therapy for the prevention and treatment of SCD have taken place. This unfavorable trend is a consequence of our inability to identify those who will die suddenly from lethal ventricular arrhythmias and to develop effective strategies for all populations at risk. Clinical variables such as LV ejection fraction predict mortality but are not sensitive enough to identify many patients at high-risk for SCD [11]. The predictive power of autonomic dysregulation and markers such as hyperlipidemia, hypertension, diabetes, and smoking is quite low in subclinical heart disease, the population in which the majority of SCDs occur [11]. Recent advances in genomic science now provide us with not only novel approaches to identify candidate genes or pathways, but also identify relatively common genetic variations (polymorphisms) which may predispose patients to increased risk for SCD. The greater challenge for genomic medicine, however, over the next decade is how these genetic variants modulate the risk of ventricular arrhythmias, particularly in the context of pathological (e.g., HF or infarct) or iatrogenic insults. Improved understanding of the relationship between common polymorphisms and SCD will not only improve risk stratification such that ICDs can be targeted to those patients most likely to benefit from them, but also provide new insight into the pathophysiology of SCD.

\section{Common genetic variations}

Genetic variation constitutes the uniqueness of each individual. A polymorphism is defined as a discontinuous genetic variation that results in the occurrence of several different forms or types of individuals among the members of a single species. The most obvious example of polymorphism is the separation of higher organisms into male and female sexes. A polymorphism that persists over many generations is usually maintained because no one form has an overall advantage or disadvantage over the others in terms of natural selection. However, genetic variations in genes that encode proteins important for cellular physiology and function such as ion channel regulation and flux may be deleterious and could be selected against in a population. Usually, when genetic variation exists in a gene, there is a predominant form (allele) 
in the population, with one or more minority forms (alleles). Although genetic variations could arise de novo in a founder individual, it takes many generations before they will be randomly and equally distributed in a population. The second explanation for unequal population frequencies for certain genetic variants is that specific variations may carry a selection disadvantage with regards health and disease.

While the final common pathway for SCD is malignant ventricular arrhythmia, there are many potential contributors, pathways, and mechanisms by which variant alleles could affect initiation and propagation of life-threatening cardiac arrhythmias (Fig. 1). Consequently, genetic variations in genes encoding for proteins involved in these critical pathways may lead to exaggerated or decompensatory response in the context of atherosclerosis and thrombosis, electrogenesis and propagation, and even initiating triggers and select against the specific genetic variation, maintaining its presence at a lower population frequency.

\section{Polymorphisms associated with increased risk of ventricular arrhythmia in the presence of acquired risk factors}

It is now generally accepted that many common polymorphisms, usually defined as a population frequency greater than $1 \%$, have physiological or functional consequence. For a long time it was assumed that development of polymorphic ventricular tachycardia upon exposure to a QT prolonging drug was deemed an adverse reaction (so called 'acquired long QT syndrome'). However, the observation that mutations in a number of ion channel genes are responsible for familial or congenital long QT syndrome raised the possibility of the influence of population variants of these genes in the 'acquired' form of long QT syndrome. Yang and colleagues [12] investigated the role of genetic variants in modulating the risk of torsades de pointes and found subclinical long QT syndrome mutations in 10-20\% of subjects who develop this arrhythmia. We have proposed the idea of 'repolarization reserve' which suggests that multiple mechanisms contribute to normal repolarization, so that removal of any one of these (by disease, subclinical mutation or polymorphism in an ion channel or other gene) may be without consequence until a drug is added at which point the 'reduced repolarization reserve' becomes evident by marked QT prolongation and torsades de pointes [13].

In another report, a variant allele for the cardiac sodium channel gene SCN5A (Ser1102Tyr) was found to be widespread among African Americans (13\%) and African Caribbeaners (19\%), whereas it is not found in either Asians or whites. This polymorphism was associated with prolongation of the QT interval and drug-induced arrhythmias [14]. The extent to which polymorphisms of cardiac ion channels explain proarrhythmic responses to drugs is unknown. On the other hand, the interaction of silent common genetic variants with more general physiologic states, such as enhanced catecholamine drive, and pathologic states, such as acute ischemia, remains to be determined.

\section{Mechanisms of SCD}

In one sense, SCD can be considered an electrical accident because, although many individuals have anatomic and functional substrates conducive to developing a life-threatening ventricular arrhythmia and many patients have transient events that could predispose to the initiation of ventricular tachycardia (VT) or VF, only a relatively small number of patients actually do develop SCD. It is the interplay between the anatomic and functional substrates, modulated by the transient events that perturb the balance, and the impact of all three on the underlying potential arrhythmia mechanisms possessed by all hearts that precipitates SCD (Fig. 1).

The figure also serves to illustrate the complexity as well as the potential variations in the inciting factors, because each category in the diagram can interact with the others in almost 
endless permutations and combinations. Quite often, one element in one category can interact with a single item in another category and not produce SCD unless one of the abnormalities is extremely severe. For example, mild hypokalemia with a potassium concentration of $2.7 \mathrm{mEq} /$ 1 alone is insufficient to cause a problem. Even in a patient with stable coronary artery disease (CAD) that combination may not necessarily be lethal. However, if combined with preexisting reentry pathways in the ventricular myocardium, perhaps due to an old infarction, then the combination of the three elements, i.e., CAD, scarred myocardium, and hypokalemia, might be sufficient to provoke ventricular tachyarrhythmias, causing SCD.

In addition to the critical role played by cardiac ion channels in cellular electrophysiology, other molecular pathways are critically involved in the pathogenesis of ventricular arrhythmias. The remainder of this article will discuss some of these pathways and the possible role of genetic variations within critical genes (Table 1).

\section{$\beta$-Adrenergic receptor signaling cascade}

Considerable amount of basic and clinical data attests to the critical role of the autonomic nervous system in SCD mechanisms [15-17]. One potential trigger for fatal arrhythmias in patients with ischemic heart disease or HF may come from an imbalance of the parasympathetic and sympathetic nervous systems, the latter being mediated by Cardiac $\beta_{1}$ - and $\beta_{2}$-adrenergic receptors. Indeed, treatment with $\beta$-blockers of patients with HF and those who have suffered a myocardial infarction (MI) significantly reduces ventricular tachyarrhythmias and SCD. The pathophysiology of SCD is usually considered in terms of the underlying disease. However, there is emerging evidence for genetic variability of the $\beta_{1}$-adrenergic receptor $\left(\beta_{1} \mathrm{AR}\right)$ and $\beta_{2}$-adrenergic receptor $\left(\beta_{2} \mathrm{AR}\right)$ genes that have functional consequence in transfected cells, endogenously expressing cells, and transgenic mice $[18,19]$. Familial clustering of ventricular arrhythmias and the unexplained variability in susceptibility among unrelated individuals to fatal arrhythmias provides additional support for common genetic variations in the $\beta_{1} \mathrm{AR}$ or $\beta_{2} \mathrm{AR}$ genes as risk factors for SCD.

\section{$\beta_{1}$-AR polymorphisms}

Three $\beta$-blockers have been shown to reduce the risk of SCD and total mortality in large-scale, placebo-controlled randomized clinical HF trials. Treatment with bisoprolol in cardiac insufficiency bisoprolol study (CIBIS)-II [20] significantly reduced SCD (4 vs. $6 \%, P=$ $0.0011)$, as did treatment with metoprolol succinate (4 vs. $7 \%, P=0.0002)$ in metoprolol CR/ $\mathrm{XL}$ randomized intervention trial in congestive heart failure (MERIT-HF) [21]. Similar survival benefits were reported for the nonselective $\beta_{1}-/ \beta_{2}$-blocker carvedilol in the US carvedilol heart failure study group ( 2 vs. $4 \%$ for SCD for carvedilol and placebo, respectively) [22].

Although numerous polymorphisms have been identified in the $\beta_{1}$-AR gene, the Ser 49 Gly and the Arg389Gly polymorphisms have been shown to have functional consequence in model expression systems. The Ser49Gly polymorphism with a minor allele frequency of $22 \%$ has been demonstrated to modulate receptor sensitivity [23]. In clinical studies, variation in the amino acid residue at this location has been shown to influence resting heart rate and survival in a small heart failure cohort $[24,25]$. In transfected fibroblasts stimulated with isoproterenol, the Arg389Gly polymorphism (allele frequency $26 \%$ ) has been shown to increase response to adenyl cyclase suggesting that variation in this polymorphism may influence arrhythmia incidence in patients with heart failure [26,27]. 


\section{$\beta_{2}$-AR polymorphisms}

The $\beta_{2}$-AR gene has two common polymorphisms one at nucleotide 46 (codon 16), where the translated amino acids are either Arg or Gly, and another one at nucleotide 79 (codon 27), where Gln or Glu can be found. A rare variant at nucleotide 491 (codon 164) also has been identified, where $\mathrm{Thr}$ is most common and Ile is the minor allele. Early functional studies revealed that the Ile164 receptor is markedly defective in signaling to $\mathrm{G}_{\mathrm{s}} /$ adenylyl cyclase [28]. In contrast, the more common variants all appeared to have similar signaling to $\mathrm{G}_{\mathrm{s}} /$ adenylyl cyclase under base-line conditions. However, when the receptors were exposed to isoproterenol for $24 \mathrm{~h}$, agonist-promoted downregulation of the Gly16/Glu27 receptor was enhanced $~ 50 \%$ compared with Arg16/Glu27 [29]. Importantly, the Gly16 phenotype was observed regardless of whether the position 27 amino acid was Glu or Gln. Recently, in a follow-up of subjects enrolled in the cardiovascular health study (CHS), it has been shown that homozygosity for Gln27 is associated with increased risk for SCD compared with those subjects with one or two Glu27 alleles (Glu27 carriers) [30]. Although there was no association with the polymorphisms at amino acid 16 , as $\beta_{2}$-AR polymorphisms occur in various combination (haplotypes or, in the case of two variable positions, diplotypes), the specific diplotype Gly16/Gln27 may be the more robust indicator of SCD risk than the others indicating a role for the position 16 residue [31].

\section{Renin-angiotensin-aldosterone (RAAS) cascade}

The experimental and clinical literature that has accumulated over the last 30 years provides incontrovertible evidence for a close relationship between activation of the adrenergic RAAS and the progression of structural and functional myocardial changes of HF [32,33]. Importantly, extensive clinical studies have confirmed the importance of the RAAS in the pathophysiology of HF. A long series of clinical trials have uniformly shown that angiotensin converting enzyme (ACE) inhibitors provide survival benefits in patients with HF or MI. In a meta-analysis of 15 randomized controlled trials comparing ACE inhibitors with placebo in patients following acute MI, ACE inhibitor therapy resulted in a significant reduction not only in death, but also SCD [34]. The reduction in SCD risk seems therefore, to be an important component of the survival benefit observed with ACE inhibitor therapy.

The increased risk of SCD in patients with HF and activation of the RAAS may be mediated through myocardial hypertrophy and fibrosis. Myocardial fibrosis is strongly correlated with RAAS activation, especially angiotensin II and aldosterone and chronic exposure to high levels of circulating and/or tissue angiotensin may predispose to both LV and myocardial fibrosis. In animal models, SCD in transgenic mice with HF is correlated to high myocardial fibrosis (collagen) content [35,36]. Furthermore, blockade of the angiotensin II receptor type 1 by losartan has been shown to reverse and attenuate myocardial fibrosis in a transgenic HF model [37]. Taken together, the clinical and animal studies indicate that activation of the RAAS plays a critical role not only in promoting myocardial fibrosis, but also confers increased risk for SCD in HF patients.

The ACE gene contains a common polymorphism based on the presence (insertion $[I]$ ) or absence (deletion $[D]$ ) of a 287-base-pair (bp) intronic DNA segment, resulting in three genotypes ( $D D$ and II homozygotes, and $I D$ heterozygotes). The frequency of $A C E D D$ genotype has been reported to be increased in patients with MI [38], dilated cardiomyopathy, and SCD [38-40]. Although one recent study showed that HF patients carrying the $D D$ genotype were more likely to die from progressive pump failure rather than SCD, the differential use of ACE inhibitors in the two groups (i.e., $D D$ versus $D I / I I$ ) may have influenced the results [41]. Nonetheless, it is possible that common genetic variations in the RAAS cascade may predict the mode of death in HF patients. Although a single polymorphism is unlikely to 
be sufficient for risk stratification and ICD decision-making, it is possible that a group of common genetic variations may predict likelihood of mode of death in HF populations.

Other proteins that play a critical role in activation of the RAAS cascade include angiotensinogen, angiotensin II receptor type 1, and aldosterone synthase [42]. Although a number of common genetic variants have been identified for each of these proteins, whether these proteins confer an increased risk for SCD have not yet been fully evaluated in clinical studies.

\section{Intercellular cell-to-cell electrical coupling}

Electrical activation of heart requires cell-to-cell movement of current via gap junctions, arrays of densely packed protein channels that permit intercellular passage of ions and small molecules [43]. Gap junctions are clusters of transmembrane channels that connect the intercellular compartments of cells, forming sites of low-resistance electrical resistance for electrical conduits for the passage of current. As transfer of depolarizing current can occur only at gap junctions, it follows that the spatial distribution and biophysical properties of gap junction channels are important determinants of the velocity and 3-D pattern of electrical activation of the heart.

One critical element necessary for reentrant arrhythmias is regional variability in conduction velocity creating localized asymmetry in the depolarizing wavefront through zones of tissue [44]. Such a substrate promotes reentry, whereby depolarizing wavefronts continually reenter themselves. Thus, defects in the function of gap junctions may be predicted to predispose myocardial tissue to reentry arrhythmias. Gap junctions are composed of members of a multigene family of proteins called connexins. Although individual cells express multiple connexins, which create the potential for considerable functional diversity in gap junction channels, the predominant connexin form in the ventricle is connexin 43. Importantly, animal studies provide compelling evidence that reduced expression of connexin 43 accelerates the onset and increases the incidence, frequency, and duration of ventricular tachyarrhythmias [45]. Mice deficient in connexin 43 not only experienced more spontaneous ventricular arrhythmias, but also VT could be more easily induced when compared to wild-type control mice $[46,47]$. Despite this compelling evidence of the critical role of connexins in arrhythmogenesis, contemporary research in this field has so far focused on evaluating altered expression of connexin mRNA in patients with HF and there have been no systematic studies performed to identify common connexin genetic variants in cohort populations at high-risk for SCD.

\section{Atherosclerosis and thrombosis cascade}

Although the majority of SCD occurs in patients with atherosclerosis (65-85\%) [1], there is considerable evidence that traditional risk factors markers for CAD, such as hypertension, obesity, smoking, diabetes, and lipid abnormalities, are not specific enough to identify patients at high-risk for SCD. Despite genetic association between facilitators of CAD and SCD, most of these markers remain indicators of predisposing conditions rather than markers of ventricular arrhythmogenesis per se. Although there is overlap in causation, there is also dissociation between the two; a distinction readily apparent in the clinical observation that at least half of all SCD events likely occur in subjects with normal lipid and lipoprotein levels and a virtual absence of elevations in other conventional risk factors [48]. Although they are obviously contributory, the predisposing influences on risks for CAD are clearly not necessarily indicators of arrhythmias or SCD in all individuals. Furthermore, patients with similar risk factors for CAD may suffer from SCD or nonfatal ischemic events. Although the explanation for this difference is far from clear, data from a recent case-control strongly suggest that there is a genetic predisposition to primary VF in the setting of an acute MI [49]. Furthermore, there is new understanding of the cascade that relates the distal events of atherosclerosis to the 
proximal event of SCD. New risk markers for SCD in CAD are likely to cluster under factors that may directly facilitate the development of acute coronary syndromes, specifically those factors that may facilitate transient triggering events, including plaque rupture, enhanced thrombogenesis, and coronary artery spasm.

Observations such as heritable alterations in matrix metalloproteinase (for instance, stromelysin) [50], which promote degradation of the fibrin cap, are emerging to support genetic variation playing a role in acute plaque rupture. Also, molecular variants within pathways of platelet adhesion, arterial thrombosis, and the clotting cascade appear to be likely candidates for enhancing SCD susceptibility. Formation of a platelet-rich thrombus is mediated via binding of fibrin to the activated platelet glycoprotein IIb/IIIa receptor, and heightened platelet aggregation, for example, is associated with increased mortality and SCD in patients with CAD who have the A2 allele of the $\mathrm{PI}^{\mathrm{A} 2}$ polymorphism in the IIIa gene [51,52]. A subsequent study in the same population examined the $\alpha_{2 \mathrm{~B}}$-adrenoreceptor insertion/deletion polymorphism, previously associated with increased risk for acute MI. The deletion/deletion genotype was associated with an increased risk for SCD when compared to subjects with the insertioninsertion genotype [53]. Another study by Anvari et al. [54] examined the SCD impact of the plasminogen activator inhibitor type I (PAI-I) 4G/5G polymorphism. The 4G polymorphism was selected based on association with both PAI-I plasma levels and an apparent increase in coronary ischemia [55]. The investigators genotyped $97 \mathrm{CAD}$-positive survivors of SCD who received ICDs and had known associated CAD as well as 113 controls with CAD and a negative history of ventricular arrhythmias. An additive genetic risk was associated with the $4 \mathrm{G}$ allele and they also demonstrated that PAI-I plasma levels were higher in SCD subjects than controls, even when stratified by genotype. Together the data strongly support a role for PAI-I in SCD.

Genetic variations that predispose to vasospasm and other vascular changes that lead to ischemic arrhythmias have also been variously reported in the full physiological range of mediators that influence the vascular endothelium and smooth muscle. This would include those that affect responses to adrenergic, cholinergic, hormonal, and metabolic factors, as well as local mechanisms of control. One recent example of the latter was noted in studies on the vascular endothelial nitric oxide (NO) synthase (eNOS) system. Changes in tissue NO levels occur in patients with chronic hypertension, atherosclerosis, and thrombotic disorders, and polymorphic forms of eNOS have been described [56], as have mutations in the promoter sequence for this gene [57]. One variant, the eNOS $4 / 4$ allele, appears particularly sensitive to an environmental influence (cigarette smoke), and inducible changes in eNOS gene expression may be a useful model for the study of external influences on triggering SCD in high-risk genotypes.

\section{Calcium homeostasis cascade}

$\mathrm{Ca}^{2+}$ plays an important role in the excitation-coupling (E-C) cycle of the human heart. Upon excitation plasmalemmal L-type $\mathrm{Ca}^{2+}$ channels open and an influx of $\mathrm{Ca}^{2+}$ follows causing $\mathrm{Ca}^{2+}$-induced $\mathrm{Ca}^{2+}$ release from the sarcoplasmic reticulum (SR) through ryanodine receptors in the SR membrane [58]. If the tight regulation of intra-cellular $\mathrm{Ca}^{2+}$ is compromised, ventricular arrhythmias and SCD may occur as seen in patients with mutations in either the cardiac ryanodine receptor type II $(R y R 2)$ [59], calsequestrin $(C A S Q 2)[60,61]$ or the gene encoding the $\alpha$-subunit of the L-type $\mathrm{Ca}^{2+}$ channel $(C A C N A 1 C)$ [62,63]. Following contraction, cytoplasmic $\mathrm{Ca}^{2+}$ is transported back into the SR by a Ca ${ }^{2+}$ ATPase (SERCA2) located in the SR membrane. The function of SERCA2 is tightly regulated by two small homologous polypeptides, phospholamban (PLN), and sarcolipin (SLN) [64].

As HF is a condition characterized by impaired cellular calcium handling, it can be postulated that genetic variation in any of the three important signaling cascades that regulate cardiac E- 
C coupling (i.e., the L-type channel [ $\mathrm{Ca}^{2+}$ influx pathway], phospholamban which regulates SERCA2A activity [the SR Ca ${ }^{2+}$ uptake pathway], and the RyR2 [the $\mathrm{SR} \mathrm{Ca}^{2+}$ release pathway]) may increase the risk for ventricular arrhythmias in patients with HF. Although the genes encoding for proteins important for $\mathrm{Ca}^{2+}$ homeostasis have been cloned, there are no reports of screening for genetic variants of these genes in at-risk arrhythmia populations. Importantly, common genetic variants in $R y R 2$ (Gln2958Arg, allele frequency 20-30\%), and the sodium-calcium exchanger (Glu692Val, allele frequency $~ 5 \%$ ), which acts in combination with SER-CA2A to resequester $\mathrm{Ca}^{2+}$ in the SR, have been identified and deposited in the single nucleotide polymorphism data-bank (dbSNP; http://www.ncbi.nlm.nih.gov/projects/SNP/).

\section{Current and future directions}

Over the last two decades, genetic linkage-based studies have proved very effective in identifying causal genetic factors in Mendelian (single gene) disorders. However, these methods have had little success when applied to identifying genetic determinants of common disorders or complex traits such as SCD. In particular, there has been poor replication among studies, whereby an initial study identified a genotype with large estimated genetic effects but subsequent studies have failed to corroborate the results. In part, this reflects the dependence of linkage-based studies on unusually informative families, which can induce a bias toward rare, semi-Mendelian disease subsets in subpopulations. However, recent reports of successful identification of genetic variants in common or complex diseases using an approach that circumvents this limitation—genome-wide association (GWA) studies—have generated considerable interest.

Recently, GWA studies have been used to investigate common and complex traits such as coronary artery disease [65,66], atrial fibrillation [67], prolonged QT interval, and SCD [68, 69]. Following on from the discovery that common polymorphisms in the $5^{\prime}$ regulatory region of NOS1AP, encoding the protein Capon, modulate QTc, investigators are now examining the role of this set of variants in mediating SCD susceptibility in the NHLBI's ARIC (athereoscelerosis risk in communities) and CHS (cardiovascular health study-total enrollment $>20,000$ ), longitudinal studies. A variant NOSIAP allele present in $\sim 35-40 \%$ of European-derived US Caucasians, which prolongs QTc $~ 4-9 \mathrm{~ms}$, significantly increased midlate life absolute SCD risk 3-4\% over a 10 to 12-year-period. Relative hazard ratios (HR) for carriers of a single variant allele are $\sim 1.31$ and $\sim 1.79$ for two-copy homozygotes when adjusted for other known risk factors. These findings represent the first successful demonstration that variants in any gene convey a substantial SCD risk in the general population. Additional GWA studies are examining genomic predictors of ventricular arrhythmias in patients receiving ICDs for primary prevention of SCD.

Although a remaining problem with large GWA studies is the cost of genotyping, one recent study provided evidence that sample pooling strategies might help to overcome this issue [70]. Furthermore, as the trends observed in recent GWA studies are anticipated to continue, chips with over 1,000,000 million SNPs have recently been launched with an improvement in genotying accuracies and reduced cost. Cohort sizes are steadily increasing and DNA biobanks of unparalleled size are being established. Perhaps the greatest impact of genomics to date has been at the phenotypic level, highlighting the need for much finer resolution in our clinical diagnostic classification. A key challenge in contemporary translational medicine, particularly in the application of genomic technologies to the bedside, is accurate definition of endophenotypes, the first step in creating subsets of patients for subsequent genomic analysis. SCD can be considered an archetype for many other complex traits, where dilution of genetic effects by etiologic heterogeneity and substantial environmental influence makes systematic dissection challenging. It is anticipated that biomarker endophenotypes such as gene expression, proteomic, metabolomic, and imaging biomarkers may allow us better phenotypic 
discrimination. As determinants of complex traits such as SCD are identified, genetic stratification will become possible, potentially reducing the genetic complexity of traits and enabling the identification of additional association signals. Over the next decade, GWA studies will likely identify the major SCD risk alleles. However, whether such a marker set of high-risk alleles will adequately discriminate and be clinically applicable, will require prospective evaluation in large well-phenotyped cohorts.

\section{Conclusions}

New genomic approaches such as high-density mapping of marker single nucleotide polymorphisms and assessment of genomic structure, together with identification of critical elements in functional pathways, have began to provide important clues to identifying genetic susceptibilities to lethal ventricular arrhythmias. Although ICDs are the only effective form of treatment to prevent SCD, with the broadening of the clinical indications, it is likely that a greater number of patients receiving ICDs may never require this therapy. Identification of common genetic variants in critical signaling pathways that culminate in the final common pathway for SCD will provide us with the opportunity to better risk stratify high-risk subsets such as those with HF.

\section{Acknowledgments}

This work was supported in part by NIH grants HL75266, HL85690, and U01 HL65962.

\section{References}

1. Association, AH. Heart disease and stroke statistics-2006 update. American Heart Association; Dallas, TX: 2006

2. Ho KK, Anderson KM, Kannel WB, Grossman W, Levy D. Survival after the onset of congestive heart failure in Framingham heart study subjects. Circulation 1993;88:107-115. [PubMed: 8319323]

3. Goldman S, Johnson G, Cohn JN, Cintron G, Smith R, Francis G. Mechanism of death in heart failure. The vasodilator-heart failure trials. The V-HeFT VA cooperative studies group. Circulation 1993;87:VI24-VI31. [PubMed: 8500236]

4. Narang R, Cleland JG, Erhardt L, et al. Mode of death in chronic heart failure. A request and proposition for more accurate classification. Eur Heart J 1996;17:1390-1403. [PubMed: 8880025]

5. Kannel WB, Plehn JF, Cupples LA. Cardiac failure and sudden death in the Framingham study. Am Heart J 1988;115:869-875. [PubMed: 3354416]

6. Moss AJ, Hall WJ, Cannom DS, et al. Improved survival with an implanted defibrillator in patients with coronary disease at high risk for ventricular arrhythmia. Multicenter automatic defibrillator implantation trial investigators. N Engl J Med 1996;335:1933-1940. [PubMed: 8960472]

7. Buxton AE, Lee KL, Fisher JD, Josephson ME, Prystowsky EN, Hafley G. A randomized study of the prevention of sudden death in patients with coronary artery disease. Multicenter unsustained tachycardia trial investigators. N Engl J Med 1999;341:1882-1890. [PubMed: 10601507]

8. Moss AJ, Zareba W, Hall WJ, et al. Prophylactic implantation of a defibrillator in patients with myocardial infarction and reduced ejection fraction. N Engl J Med 2002;346:877-883. [PubMed: 11907286]

9. Bardy GH, Lee KL, Mark DB, et al. Amiodarone or an implantable cardioverter-defibrillator for congestive heart failure. N Engl J Med 2005;352:225-237. [PubMed: 15659722]

10. Josephson M, Wellens HJ. Implantable defibrillators and sudden cardiac death. Circulation 2004;109:2685-2691. [PubMed: 15184292]

11. Zipes DP, Wellens HJ. Sudden cardiac death. Circulation 1998;98:2334-2351. [PubMed: 9826323]

12. Yang P, Kanki H, Drolet B, et al. Allelic variants in long-QT disease genes in patients with drugassociated torsades de pointes. Circulation 2002;105:1943-1948. [PubMed: 11997281] 
13. Roden DM. Taking the "idio" out of "idiosyncratic": predicting torsades de pointes. Pacing Clin Electrophysiol 1998;21:1029-1034. [PubMed: 9604234]

14. Splawski I, Timothy KW, Tateyama M, et al. Variant of SCN5A sodium channel implicated in risk of cardiac arrhythmia. Science 2002;297:1333-1336. [PubMed: 12193783]

15. Schwartz PJ, Vanoli E, Stramba-Badiale M, De Ferrari GM, Billman GE, Foreman RD. Autonomic mechanisms and sudden death. New insights from analysis of baroreceptor reflexes in conscious dogs with and without a myocardial infarction. Circulation 1988;78:969-979. [PubMed: 3168199]

16. Tomaselli GF, Zipes DP. What causes sudden death in heart failure? Circ Res 2004;95:754-763. [PubMed: 15486322]

17. Chen PS, Chen LS, Cao JM, Sharifi B, Karagueuzian HS, Fishbein MC. Sympathetic nerve sprouting, electrical remodeling and the mechanisms of sudden cardiac death. Cardiovasc Res 2001;50:409416. [PubMed: 11334845]

18. Small KM, McGraw DW, Liggett SB. Pharmacology and physiology of human adrenergic receptor polymorphisms. Ann Rev Pharmacol Toxicol 2003;43:381-411. Epub 2002 Jan 10. [PubMed: 12540746]

19. Liggett SB. Genetically modified mouse models for pharmacogenomic research. Nat Rev Genet 2004;5:657-663. [PubMed: 15372087]

20. Drummond GA, Squire IB. The cardiac insufficiency bisoprolol study II. Lancet 1999;353:1361. [PubMed: 10218556]

21. Merit-HF Study Group. Effect of metoprolol CR/XL in chronic heart failure: metoprolol CR/XL randomised intervention trial in congestive heart failure (MERIT-HF). Lancet 1999;353:2001-2007. [PubMed: 10376614]

22. Packer M, Bristow MR, Cohn JN, et al. The effect of carvedilol on morbidity and mortality in patients with chronic heart failure. US carvedilol heart failure study group. N Engl J Med 1996;334:13491355. [PubMed: 8614419]

23. Levin MC, Marullo S, Muntaner O, Andersson B, Magnusson Y. The myocardium-protective Gly-49 variant of the beta 1-adrenergic receptor exhibits constitutive activity and increased desensitization and down-regulation. J Biol Chem 2002;277:30429-30435. [PubMed: 12034720]

24. Ranade K, Jorgenson E, Sheu WH, et al. A polymorphism in the beta1 adrenergic receptor is associated with resting heart rate. Am J Hum Genet 2002;70:935-942. [PubMed: 11854867]

25. Borjesson M, Magnusson Y, Hjalmarson A, Andersson B. A novel polymorphism in the gene coding for the beta(1)-adrenergic receptor associated with survival in patients with heart failure. Eur Heart J 2000;21:1853-1858. [PubMed: 11052857]

26. Mason DA, Moore JD, Green SA, Liggett SB. A gain-of-function polymorphism in a G-protein coupling domain of the human beta1-adrenergic receptor. J Biol Chem 1999;274:12670-12674. [PubMed: 10212248]

27. Liggett SB, Mialet-Perez J, Thaneemit-Chen S, et al. A polymorphism within a conserved beta(1)adrenergic receptor motif alters cardiac function and beta-blocker response in human heart failure. Proc Natl Acad Sci USA 2006;103:11288-11293. [PubMed: 16844790]

28. Green SA, Cole G, Jacinto M, Innis M, Liggett SB. A polymorphism of the human beta 2-adrenergic receptor within the fourth transmembrane domain alters ligand binding and functional properties of the receptor. J Biol Chem 1993;268:23116-23121. [PubMed: 7901205]

29. Green SA, Turki J, Innis M, Liggett SB. Amino-terminal polymorphisms of the human beta 2adrenergic receptor impart distinct agonist-promoted regulatory properties. Biochemistry 1994;33:9414-9419. [PubMed: 7915137]

30. Sotoodehnia N, Siscovick DS, Vatta M, et al. Beta2-adrenergic receptor genetic variants and risk of sudden cardiac death. Circulation 2006;113:1842-1848. [PubMed: 16618831]

31. Liggett SB. Beta2-adrenergic receptor polymorphisms and sudden cardiac death: a signal to follow. Circulation 2006;113:1818-1820. [PubMed: 16618829]

32. Pitt B, Zannad F, Remme WJ, et al. The effect of spironolactone on morbidity and mortality in patients with severe heart failure. Randomized aldactone evaluation study investigators. N Engl J Med 1999;341:709-717. [PubMed: 10471456]

33. Sleight P. Angiotensin II and trials of cardiovascular outcomes. Am J Cardiol 2002;89:11A-16A. 16A-17A. 
34. Domanski MJ, Exner DV, Borkowf CB, Geller NL, Rosenberg Y, Pfeffer MA. Effect of angiotensin converting enzyme inhibition on sudden cardiac death in patients following acute myocardial infarction. A meta-analysis of randomized clinical trials. J Am Coll Cardiol 1999;33:598-604. [PubMed: 10080457]

35. Seidman JG, Seidman C. The genetic basis for cardiomyopathy: from mutation identification to mechanistic paradigms. Cell 2001;104:557-567. [PubMed: 11239412]

36. Takeishi Y, Walsh RA. Cardiac hypertrophy and failure: lessons learned from genetically engineered mice. Acta Physiol Scand 2001;173:103-111. [PubMed: 11678732]

37. Lim DS, Lutucuta S, Bachireddy P, et al. Angiotensin II blockade reverses myocardial fibrosis in a transgenic mouse model of human hypertrophic cardiomyopathy. Circulation 2001;103:789-791. [PubMed: 11171784]

38. Samani NJ, Thompson JR, O'Toole L, Channer K, Woods KL. A meta-analysis of the association of the deletion allele of the angiotensin-converting enzyme gene with myocardial infarction. Circulation 1996;94:708-712. [PubMed: 8772692]

39. Raynolds MV, Bristow MR, Bush EW, et al. Angiotensin-converting enzyme DD genotype in patients with ischaemic or idiopathic dilated cardiomyopathy. Lancet 1993;342:1073-1075. [PubMed: 8105309]

40. Marian AJ, Yu QT, Workman R, Greve G, Roberts R. Angiotensin-converting enzyme polymorphism in hypertrophic cardiomyopathy and sudden cardiac death. Lancet 1993;342:1085-1086. [PubMed: 8105312]

41. Bedi MS, Postava LA, Murali S, et al. Interaction of implantable defibrillator therapy with angiotensin-converting enzyme deletion/insertion polymorphism. J Cardiovasc Electrophysiol 2004;15:1162-1166. [PubMed: 15485441]

42. Pacifico A, Henry PD. Structural pathways and prevention of heart failure and sudden death. J Cardiovasc Electrophysiol 2003;14:764-775. [PubMed: 12930259]

43. Kanno S, Saffitz JE. The role of myocardial gap junctions in electrical conduction and arrhythmogenesis. Cardiovasc Pathol 2001;10:169-177. [PubMed: 11600334]

44. Spach MS, Josephson ME. Initiating reentry: the role of nonuniform anisotropy in small circuits. J Cardiovasc Electrophysiol 1994;5:182-209. [PubMed: 8186887]

45. Lerner DL, Yamada KA, Schuessler RB, Saffitz JE. Accelerated onset and increased incidence of ventricular arrhythmias induced by ischemia in Cx43-deficient mice. Circulation 2000;101:547-552. [PubMed: 10662753]

46. Gutstein DE, Morley GE, Tamaddon H, et al. Conduction slowing and sudden arrhythmic death in mice with cardiac-restricted inactivation of connexin43. Circ Res 2001;88:333-339. [PubMed: 11179202]

47. Yao JA, Gutstein DE, Liu F, Fishman GI, Wit AL. Cell coupling between ventricular myocyte pairs from connexin43-deficient murine hearts. Circ Res 2003;93:736-743. [PubMed: 14500334]

48. Thompson CA, Yarzebski J, Goldberg RJ, Lessard D, Gore JM, Dalen JE. Changes over time in the incidence and case-fatality rates of primary ventricular fibrillation complicating acute myocardial infarction: perspectives from the Worcester heart attack study. Am Heart J 2000;139:1014-1021. [PubMed: 10827382]

49. Dekker LR, Bezzina CR, Henriques JP, et al. Familial sudden death is an important risk factor for primary ventricular fibrillation: a case-control study in acute myocardial infarction patients. Circulation 2006;114:1140-1145. [PubMed: 16940195]

50. Gnasso A, Motti C, Irace C, et al. Genetic variation in human stromelysin gene promoter and common carotid geometry in healthy male subjects. Arterioscler Thromb Vasc Biol 2000;20:1600-1605. [PubMed: 10845878]

51. Weiss EJ, Bray PF, Tayback M, et al. A polymorphism of a platelet glycoprotein receptor as an inherited risk factor for coronary thrombosis. N Engl J Med 1996;334:1090-1094. [PubMed: 8598867]

52. Mikkelsson J, Perola M, Laippala P, Penttila A, Karhunen PJ. Glycoprotein IIIa Pl(A1/A2) polymorphism and sudden cardiac death. J Am Coll Cardiol 2000;36:1317-1323. [PubMed: 11028489] 
53. Snapir A, Mikkelsson J, Perola M, Penttila A, Scheinin M, Karhunen PJ. Variation in the alpha2Badrenoceptor gene as a risk factor for prehospital fatal myocardial infarction and sudden cardiac death. J Am Coll Cardiol 2003;41:190-194. [PubMed: 12535806]

54. Anvari A, Schuster E, Gottsauner-Wolf M, Wojta J, Huber K. PAI-I 4G/5G polymorphism and sudden cardiac death in patients with coronary artery disease. Thromb Res 2001;103:103-107. [PubMed: 11457467]

55. Iwai N, Shimoike H, Nakamura Y, Tamaki S, Kinoshita M. The 4G/5G polymorphism of the plasminogen activator inhibitor gene is associated with the time course of progression to acute coronary syndromes. Atherosclerosis 1998;136:109-114. [PubMed: 9544737]

56. Wang XL, Sim AS, Wang MX, Murrell GA, Trudinger B, Wang J. Genotype dependent and cigarette specific effects on endothelial nitric oxide synthase gene expression and enzyme activity. FEBS Lett 2000;471:45-50. [PubMed: 10760510]

57. Nakayama M, Yasue H, Yoshimura M, et al. T-786 $\rightarrow$ C mutation in the 5'-flanking region of the endothelial nitric oxide synthase gene is associated with coronary spasm. Circulation 1999;99:28642870. [PubMed: 10359729]

58. Bers DM. Cardiac excitation-contraction coupling. Nature 2002;415:198-205. [PubMed: 11805843]

59. Priori SG, Napolitano C, Tiso N, et al. Mutations in the cardiac ryanodine receptor gene (hRyR2) underlie catecholaminergic polymorphic ventricular tachycardia. Circulation 2001;103:196-200. [PubMed: 11208676]

60. Terentyev D, Viatchenko-Karpinski S, Gyorke I, Volpe P, Williams SC, Gyorke S. Calsequestrin determines the functional size and stability of cardiac intracellular calcium stores: mechanism for hereditary arrhythmia. Proc Natl Acad Sci USA 2003;100:11759-11764. [PubMed: 13130076]

61. Lahat H, Pras E, Olender T, et al. A missense mutation in a highly conserved region of CASQ2 is associated with autosomal recessive catecholamine-induced polymorphic ventricular tachycardia in Bedouin families from Israel. Am J Hum Genet 2001;69:1378-1384. [PubMed: 11704930]

62. Splawski I, Timothy KW, Sharpe LM, et al. Ca(V)1.2 calcium channel dysfunction causes a multisystem disorder including arrhythmia and autism. Cell 2004;119:19-31. [PubMed: 15454078]

63. Splawski I, Timothy KW, Decher N, et al. Severe arrhythmia disorder caused by cardiac L-type calcium channel mutations. Proc Natl Acad Sci USA 2005;102:8089-8096. [PubMed: 15863612]

64. MacLennan DH, Asahi M, Tupling AR. The regulation of SERCA-type pumps by phospholamban and sarcolipin. Ann N Y Acad Sci 2003;986:472-480. [PubMed: 12763867]

65. Ozaki K, Ohnishi Y, Iida A, et al. Functional SNPs in the lymphotoxin-alpha gene that are associated with susceptibility to myocardial infarction. Nat Genet 2002;32:650-654. [PubMed: 12426569]

66. Samani NJ, Erdmann J, Hall AS, et al. Genomewide association analysis of coronary artery disease. N Engl J Med 2007;357:443-453. [PubMed: 17634449]

67. Gudbjartsson DF, Arnar DO, Helgadottir A, et al. Variants conferring risk of atrial fibrillation on chromosome 4q25. Nature 2007;448(7151):353-357. [PubMed: 17603472]

68. Arking DE, Pfeufer A, Post W, et al. A common genetic variant in the NOS1 regulator NOS1AP modulates cardiac repolarization. Nat Genet 2006;38:644-651. [PubMed: 16648850]

69. Newton-Cheh C, Larson MG, Corey DC, et al. QT interval is a heritable quantitative trait with evidence of linkage to chromosome 3 in a genome-wide linkage analysis: the Framingham heart study. Heart Rhythm 2005;2:277-284. [PubMed: 15851319]

70. Baum AE, Akula N, Cabanero M, et al. A genome-wide association study implicates diacylglycerol kinase eta (DGKH) and several other genes in the etiology of bipolar disorder. Mol Psychiatry 2008;13:197-207. [PubMed: 17486107] 


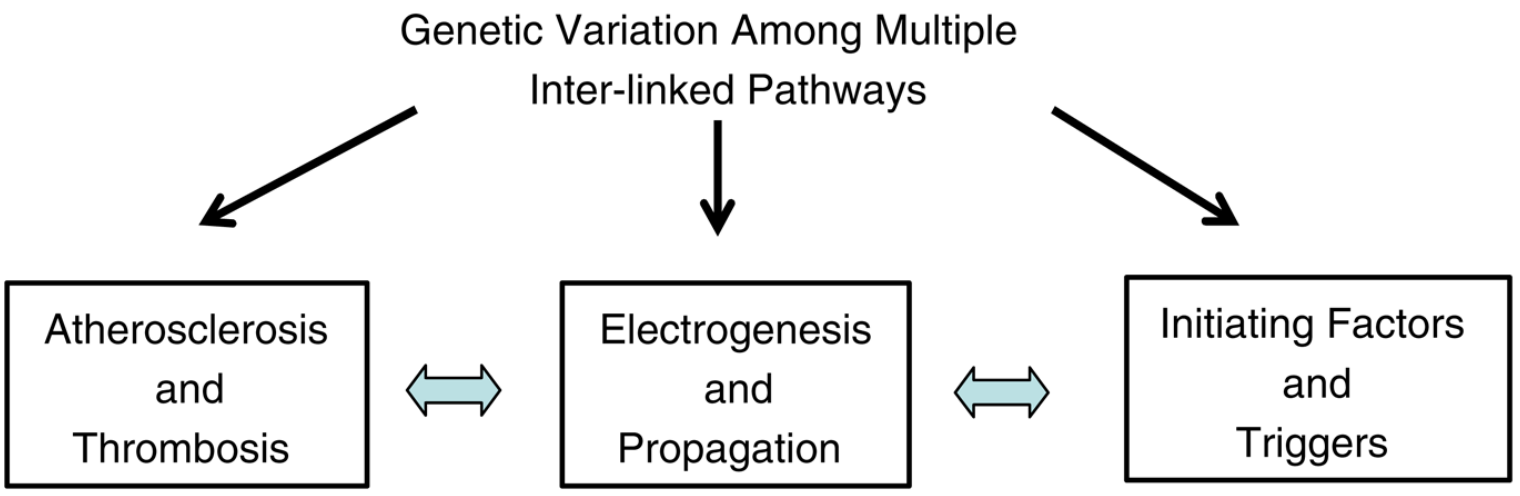

Plaque formation and stability Cholesterol metabolism

Ion channels $\left(\mathrm{Na}^{+}\right.$and $\mathrm{K}^{+}$) $\mathrm{Ca}^{2+}$ homeostasis Hemostasis and clotting cascade Inflammatory mediators Vascular factors
Connexins and gap junctions Myocardial remodeling (scarring, fibrosis, disarray) Myocardial energetics and redox

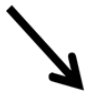

Central neural modulation Sympathetic/parasympathetic Receptor and signaling cascade , Ischemia and ionic regulation Vasomotor modulation

\title{
SUDDEN CARDIAC DEATH
}

\author{
Ventricular Tachycardia \\ Ventricular Fibrillation
}

Fig. 1.

Mechanistic pathways through which genetic variations in susceptible individuals could affect mechanisms of initiation of arrhythmogenesis, propagation, and conduction of aberrant electrical impulses and transitions between potentially lethal ventricular tachyarrhythmias leading to SCD. Potential and documented elements of potential risk are depicted for three broad categories: (1) those that lead to atherosclerosis and overt coronary artery disease and the likelihood of myocardial infarction and ischemic arrhythmias; (2) those involved in electrogenesis and myocardial conduction pathways; and (3) those that may influence initiation of triggering events and perpetuation of an arrhythmia. Adapted from Spooner PM, Albert C, Benjamin EJ, Boineau R, Elston RC, et al (2001) Sudden cardiac death genes, and arrhythmogenesis: consideration of new population and mechanistic approaches from a National Heart, Lung, and Blood Institute workshop, part II. Circulation 103:2447-2452, by permission of the American Heart Association 2007 
Table 1

Common genetic variations in signaling pathways important in the pathogenesis of sudden cardiac death

\begin{tabular}{|c|c|c|c|}
\hline Gene & Polymorphism and amino acid change & Functional characterization & Population frequency $(\%)$ \\
\hline$\alpha_{2}$-Adrenergic receptor & Insertion/deletion & $\begin{array}{l}\text { Deletion variant impairs agonist- } \\
\text { promoted receptor } \\
\text { desensitization }\end{array}$ & 22 \\
\hline \multirow[t]{2}{*}{$\beta_{1}$-Adrenergic receptor } & Serine49Glycine & Modulates resting heart rate & 22 \\
\hline & Arginine389Glycine & $\begin{array}{l}\text { Increase response to adenyl } \\
\text { cyclase }\end{array}$ & 26 \\
\hline \multirow[t]{2}{*}{$\beta_{2}$-Adrenergic receptor } & Glycine16Glutamine & Enhanced response to agonists & \\
\hline & Glycine27Glutamine & Enhanced response to agonists & \\
\hline \multirow[t]{2}{*}{ Angiotensinogen } & Threonine207Methionine & & 7 \\
\hline & Methionine268Threonine & & 30 \\
\hline \multirow[t]{3}{*}{ Angiotensin II type 1 receptor } & Alanine163Threonine & & 7 \\
\hline & Alanine244Serine & & 2 \\
\hline & $\begin{array}{l}\text { 3'untranslated region with adenine/ } \\
\text { cytosine }\end{array}$ & & 22 \\
\hline Angiotensin converting enzyme & $\begin{array}{l}\text { 287-base-pair intronic insertion }(I) / \\
\text { deletion }(D)\end{array}$ & $\begin{array}{l}\text { Increased angiotensin II in } D D \\
\text { individuals }\end{array}$ & 25 \\
\hline Aldosterone synthetase & Lysine173Arginine & & 27 \\
\hline \multirow{2}{*}{$\begin{array}{l}\text { Delayed rectifier potassium } \\
\text { channel }(K C N H 2)\end{array}$} & Lysine897Threonine & & 20 \\
\hline & Glutamine1068Arginine & & 7 \\
\hline \multirow{2}{*}{$\begin{array}{l}\text { Voltage-gated sodium channel } \\
(S C N 5 A)\end{array}$} & Histidine558Arginine & & 15 \\
\hline & Serine1102Tyrosine & & 15 \\
\hline Connexin-43 & Unknown & & \\
\hline Stromelysin & 5/6Adenosine promoter polymorphism & $\begin{array}{l}\text { Modulates promoter activity and } \\
\text { increased accumulation of } \\
\text { matrix metalloproteinases }\end{array}$ & 23 \\
\hline $\begin{array}{l}\text { Platelet glycoprotein receptor IIIa } \\
(P I)\end{array}$ & Leucine33Proline & Increased platelet aggregability & 11 \\
\hline $\begin{array}{l}\text { Plasminogen activator inhibitor } \\
\text { type I (PAI-I) }\end{array}$ & $4 \mathrm{G} / 5 \mathrm{G}$ & Modulates plasma PAI-I levels & 44 \\
\hline Serca2A & Unknown & & \\
\hline Phospholamban & Unknown & & \\
\hline $\mathrm{Na}^{+} / \mathrm{Ca}^{2+}$ exchanger (NCX1) & Gultamate692Valine & & 5 \\
\hline $\begin{array}{l}\text { Ryanodine receptor type II } \\
\text { (RyR2) }\end{array}$ & Glutamine2958Arginine & & 20 \\
\hline
\end{tabular}

